\title{
Ist am Sonntag die Fünfprozenthürde verfassungswidrig geworden?
}

VB verfassungsblog.de/ist-am-sonntag-fuenfprozenthuerde-verfassungswidrig-geworden/

Maximilian Steinbeis Di 24 Sep 2013

Di 24 Sep

2013

(c) Andrew Cheal Photography, Flickr CC BY-ND 2.0

Ob die Fünfprozenthürde mit dem Grundgesetz, das gleiche Wahlchancen für alle vorschreibt, vereinbar ist, gehört zu den Klassikerfragen, die wohl jeder Jurastudent in irgendeiner Staatsrechtsklausur irgendwann mal durchgeprüft hat. Spätestens seit das BVerfG vor knapp zwei Jahren diese Hürde bei der Europawahl gekippt hat, ist das keine akademische Fragestellung mehr. Und schon gar nicht ist sie das seit letztem Sonntag.

Noch nie hat die Fünfprozenthürde so viele Stimmen aus dem Prozess gefiltert wie diesmal. Fast fünfzehn Prozent der Wähler, in absoluten Zahlen knapp sieben Millionen haben ihr Kreuzchen für die Tonne gemacht - so viel wie die Einwohner Thüringens und Sachsens zusammen, wie SpOn ausgerechnet hat.

Und, ist sie nun verfassungswidrig, die Sperrklausel? Auch das BVerfG hatte darüber schon das eine oder andere Mal zu befinden, zuerst in einer seiner ersten Entscheidungen überhaupt aus dem Jahr 1952. Da entstand (für das bundesrepublikanische Verfassungsrecht) die bis zum Überdruss wiederholte Staatsrechtsklausur-Einbimsformel von der Zähl- und Erfolgswertgleichheit im Wahlrecht: In einem Verhältniswahlsystem müssen die Stimmen nicht nur nominell, sondern auch in ihren Einflusschancen für die Zusammensetzung des Bundestages das gleiche Gewicht haben. Diese Erfolgswertgleichheit muss aber in Balance zu einem anderen Verfassungsprinzip gesetzt werden, nämlich dass die Wahl ein handlungs- und mehrheitsbildungsfähiges Parlament hervorbringen muss. Soweit die Sperrklausel tatsächlich hilft, eine Zersplitterung des Bundestages durch lauter Kleinparteien zu vermeiden, ist sie somit verfassungsrechtlich okay.

Einstweilen galt somit die Sperrklausel als verfassungsgemäß, und jeder Jurastudent, der zu einem anderen Schluss gekommen wäre, hätte (zumindest zu meiner Zeit in München Anfang der 90er Jahre) große Schwierigkeiten gehabt, über die 4 Punkte zu kommen.

Aber stimmt das noch? Das BVerfG sagt seit langem und hat in der Europawahl-Entscheidung 2011 nochmal sehr wortreich ausgeführt, dass die Frage der Verfassungsmäßigkeit der Fünfprozenthürde sich in jeder neuen Situation neu stellt:

\section{Der Gesetzgeber ist verpflichtet, eine die Wahlgleichheit und die Chancengleichheit berührende Norm des Wahlrechts zu überprüfen und gegebenenfalls zu ändern, wenn die verfassungsrechtliche Rechtfertigung dieser Norm durch neue Entwicklungen in Frage gestellt wird (...).}

Die schiere Zahl und Größe der Parteien, die 2013 an der Sperrklausel gescheitert sind, sind zweifellos eine neue Entwicklung. Stellt sie die verfassungsrechtliche Rechtfertigung der Sperrklausel in Frage?

Gerechtfertigt wird die Klausel mit dem Ziel, die Zersplitterung des Bundestags zu vermeiden, auf dass dieser nicht handlungsunfähig werde. Was nicht passieren soll, ist ein Bundestag, in dem keine Mehrheit mehr zustande kommt, der kein Gesetz mehr ändern kann, nicht einmal mehr das Wahlgesetz auf eine Weise anpassen kann, der ihm aus dieser Gridlocksituation wieder heraushilft - kurzum: Stillstand der Gesetzespflege. 
Dieses Ziel wird erstmal nicht weniger relevant dadurch, dass Zahl und Größe der Splitterparteien steigen - eher im Gegenteil (selbst wenn sich abzeichnet, dass die Mehrheitsbildung auch so furchtbar schwierig wird).

Auch die Verhältnismäßigkeitsprüfung scheint mir nicht weiterzuführen. Wenn ich mit meiner Stimme für die Tierschutzpartei (hypothetisch!) scheitere, wird der Eingriff in mein Recht auf Wahlrechtsgleichheit nicht dadurch schlimmer, dass mit mir Millionen von FDP-, AfD- und Piratenwählern auch noch scheitern.

Wenn es einen Ansatzpunkt gibt, dann meines Erachtens der, dass die Einschränkung der Wahlrechtsgleichheit damit gerechtfertigt wird, dass die Wahl noch ihren Zweck erfüllen muss. Und dieser Zweck ist nicht nur, ein handlungsfähiges Parlament hervorzubringen, sondern eben auch ein repräsentatives. Eine Wahl, die im System der Verhältniswahl organisiert wird, erhebt den Anspruch, ein Parlament hervorzubringen, das das Meinungsspektrum des Wahlvolks wiederzuspiegelt und daraus seine Legitimation ableitet.

Bisher war dieser Anspruch nicht schon widerlegt, wenn die Anhänger der bibeltreuen Christen und der Bayernpartei aus dem Spiegelbild des Wahlvolks rausgefiltert wurden. Das Bild war durch die Sperrklausel sozusagen grobauflösend, aber trotzdem im Großen und Ganzen akkurat.

Aber jetzt? Kann man ein Bild, in dem ganze fünfzehn Prozent der Pixel fehlen, noch akkurat nennen?

Aus der bisher zweipoligen Konstellation - Gleichheit der Stimme vs. Handlungsfähigkeit des Parlaments - würde somit eine dreipolige: Gleichheit vs. Handlungsfähigkeit vs. Repräsentativität.

Wetten würde ich nicht darauf, dass Karlsruhe auf dieser Grundlage die Sperrklausel am Ende tatsächlich kippt. Aber wenn ich die FDP wäre, würde ich das mal prüfen lassen und gegebenenfalls klagen. Ich halte es jedenfalls nicht für unwahrscheinlich, dass in punkto Fünfprozenthürde das letzte Wort aus Karlsruhe noch nicht gesprochen ist.

LICENSED UNDER CC BY NC ND

SUGGESTED CITATION Steinbeis, Maximilian: Ist am Sonntag die Fünfprozenthürde verfassungswidrig geworden?, VerfBlog, 2013/9/24, http://verfassungsblog.de/ist-am-sonntag-fuenfprozenthuerde-verfassungswidriggeworden/. 